\title{
Niilismo, Política, História
}

\author{
Nihilism, Politics, History
}

Rossano Pecoraro

UFPI/CAPES-PNPD

Resumo: O objetivo deste ensaio é examinar o conceito de niilismo não nos seus aspectos teoréticoconceituais, mais no seu impacto no que podemos definir como "filosofia prática", in primis história e política. Entre os movimentos e autores abordados estão o niilismo russo, Carl Schmitt, Walter Benjamin, Alexandre Kojève, Arnold Gehlen, Gianni Vattimo.

Palavras-Chave: Niilismo, Filosofia da História, Filosofia Política, Modernidade.

Abstract: This paper claims to analyze the concept of nihilism not in its theoretic-conceptual dimensions, but on its impact over the so called "practical philosophy", in primis history and politics. Among the analyzed movements and authors are the Russian nihilism, Carl Schmitt, Walter Benjamin, Alexandre Kojève, Arnold Gehlen, Gianni Vattimo.

Key-words: Nihilism, Philosophy of history, Political philosophy, Modernity.

Desde o fim do século XVIII o niilismo - isto é, a desvalorização e a morte do sentido, a ausência de finalidade e de resposta ao "porquê"; a crise epocal em que os valores tradicionais se depreciam e os princípios e critérios absolutos se dissolvem insinuou-se na História não apenas em sua feição teorética e filosófica, como em seu mostrar-se no plano social e político.

Para examiná-lo esses fenômeno um significativo ponto de partida são a cultura francesa, alemã e russa do Ottocento. É das obras do reacionário saboiano Joseph de Maistre, por exemplo, que o pensador católico Franz von Baader recebe o conceito de niilismo, ao qual se dedica em dois ensaios de 1824 e 1826 (em plena época 
romântica). Para ele foi o protestantismo a dar origem a um fenômeno dissolutivo das verdades sagradas, isto é, ao "niilismo científico, destrutivo" que o catolicismo tem de combater impondo novamente o próprio "conceito de autoridade no sentido eclesiástico, político e científico contra todos os tipos de dúvidas ou protestos, antigos ou novos". Em seguida von Badeer refina a sua visão, definindo o niilismo como "um abuso da inteligência destrutivo para a religião", um efeito do uso demasiado livre e desinibido da razão (neste sentido se moverá também a crítica de Juan Donoso Cortés) que é estigmatizado como sintoma de degeneração e desagregação do tecido civil, religioso, social. E se na atmosfera cultural da revolução francesa o termo niilista fora utilizado para indicar aqueles que não eram nem a favor, nem contra a insurreição (um dos membros da Convenção, Anacharsis Cloots, afirmou no seu discurso que a "República dos direitos do homem não é nem teísta, nem atéia; é niilista"), deve ser assinalada aqui a definição, retomada por Krug no suplemento do seu Dicionário das ciências filosóficas, que circulava nos ambientes francês pós-revolução na qual nihiliste ou rienniste é aquele que não acredita em fé, seita, crença partido, algum, "qui ne croit à rien, qui ne s'intéresse à rien".

Ao ir além do âmbito teórico, enxertando-se no tecido da sociedade e no debate político, o niilismo impregnou a cena cultural russa nas últimas décadas do século XIX, agindo sobre componentes extremistas, anárquicas e libertárias e passando a indicar um vasto movimento de rebelião social e ideológica cujos expoentes contestavam os princípios e as ordens existentes, principalmente os ditados pela religião e pela metafísica da tradição. Mais rebelde e dogmático do que crítico e desiludido, o niilismo russo renegava o passado e condenava o presente, almejando um futuro abstratamente diverso sem possuir, porém, as forças (teóricas e práticas) para configurá-lo como uma alternativa possível, real, positiva. Individualismo, utilitarismo extremo, populismo radical, revolta contra o poder e a cultura dominantes: são estes os traços marcantes dessa forma de niilismo. Entre os personagens mais significativos devem ser destacados Nikolaj Dobroljubov, com a sua crítica ao imobilismo russo, à nobreza indiferente, apática e conservadora e o apelo à 
regeneração da sociedade mediante a arte e a literatura (será uma das fontes às quais Lukács se inspirará), e Dimitri Pisarev. Assumindo totalmente a definição de niilista delineada em Pais e filhos, Pisarev e os outros colaboradores da revista "Russkoe Slovo" pregavam um materialismo cientificista e positivista, desprezavam a arte e a religião para exaltar o individualismo, o cálculo, a ciência, o "útil”; uma atitude que não podia deixar de levar ao niilismo, isto é, à negação de valores, normas, princípios estabelecidos. Neste panorama "teórico" e perante o agravamento dos contrastes sociais e da repressão czarista, a revolta armada revolucionária encontrou terreno fértil para a sua ação.

Um dos primeiros líderes dos grupos subversivos é Nikolai Andreevic Isutin; chegado a Moscou em 1863 para terminar os seus estudos funda, pouco tempo depois, a "Organização" cujos membros se caracterizam por uma total dedicação, de cunho quase místico e ascético, ao povo e ao ideal revolucionário. A única, grande tarefa dos "organizadores" é construir uma rede capilar de propaganda e recrutamento para a futura insurreição. Um grupo restrito, chamado "O inferno", é criado para executar atos terroristas e, principalmente, matar o Czar. União, revolução, organização são as palavras-chave da atividade subversiva de Serguei Netchaiev, autor do Catecismo do revolucionário, cujo "intransigente niilismo político" vincula-se, mais uma vez, a uma posição teórica na qual se afirma a total licitude de todos os atos cuja execução possa levar à completa efetivação da causa revolucionária. O extremismo de Netchaiev foi retomado e radicalizado por Mikhail Bakunin em uma fusão incendiária de idéias anárquicas, socialistas, utópico-libertárias. "Para vencer os inimigos do proletariado é preciso destruir, ainda destruir, sempre destruir. Pois, o espírito destruidor é ao mesmo tempo o espírito construtor", repetia o revolucionário ao qual Dostoiévski se inspirou para a criação de Stavrogin, "o anjo negro" dos Demônios, e que se proclamava "fundador do niilismo e apóstolo da anarquia".

Rejeitando a violência revolucionária e o extremismo de Netchaiev e Bakunin, ao quais contrapusera a moderação, a concretude e um humanismo derivado do culto da história e da cultura, Alexandre Herzen articulou uma forma positiva de niilismo que 
considerou - embora tenha conseguido entrever os seus limites (a incapacidade de "propor novos princípios") e os seus perigos (a transformação de "idéias e fatos em puro nada", em "ceticismo estéril", em "desespero que leva à inércia") - um fenômeno construtivo, um movimento de transformação e emancipação. O niilismo, escreveu nas cartas $A$ um velho companheiro (1870), "é a lógica sem estrutura, é a ciência sem dogmas, é a incondicional obediência à experiência e a humilde aceitação de todas as suas conseqüências, quaisquer que sejam, desde que surgidas da observação e requeridas pela razão. O niilismo não transforma algo em nada, mas desvela que o nada, confundido com algo, é uma ilusão de ótica"1

A infecção do Político. As irrupções do nihil, a corrosão niilista da polis, dos seus princípios, da sua soberania devem ser pensadas de uma forma teoreticamente mais incisiva e insistente. No que diz respeito à reconstrução histórica da questão, a teologia política de Carl Schmitt é uma peça importante. Polêmico, controvertido, objeto de numerosas e conflitantes apropriações (dos teóricos do autoritarismo a Jacques Derrida) a sua reflexão põe a nu os profundos liames entre a questão da legitimidade e da soberania do Estado e o fenômeno do niilismo político. O conceito do Político, obra de 1927, parte da constatação da crise do Estado moderno, da impossibilidade de recorrer a princípios pré-políticos (teologia, visões de mundo, ideologias) capazes de fundamentar e legitimar a sua soberania. Todos os valores-base se depreciaram, perderam força, decaíram. No vazio normativo, no niilismo político da nossa época torna-se decisivo, para individuar o fundamento do poder, definir quem o detém, quem é o autêntico sujeito da soberania, isto é, individuar e estabelecer "quem decide".

O positivismo jurídico (Kelsen e a sua Grundnorm, a norma fundamental que funda, legitima, sustenta o ordenamento jurídico, isto é, o Estado) ao definir o

\footnotetext{
${ }^{1}$ Sobre a primeira parte deste capítulo ver, entre outros, MASARYK, Th. La Russia e l'Europa: studi sulle correnti spirituali in Russia, Bolonha, Boni, 1971; VENTURI, F. II populismo russo, Einaudi, Turim, 1972; VERCELLONE, F. Introduzione a II nichilismo, Laterza, Roma-Bari, 1999 (especialmente o capítulo II); VILLARI, R. Storia contemporanea, Laterza, Roma-Bari, 1993 (especialmente os capítulos III, VII, IX); VOLPI, F. II nichilismo, Laterza, Roma-Bari, 2001 (especialmente os capítulos IV e VI), PECORARO, R. O niilismo, Rio de Janeiro, Zahar, 2007.
} 
funcionamento do conjunto das normas esclarece apenas o "como" se deve decidir, mas não explica quem decide sobre este como, ou seja, quem determina o funcionamento do sistema e como isto se realiza. O positivismo pressupõe um estado de normalidade jurídica, de uma situação já efetivada que entra em crise quando se reflete sobre o momento que precede esta normalidade. É o "estado de exceção", no qual não há ainda, ou não há mais, norma alguma; é o momento da decisão fundamental, da imposição originária - de fato do nada, ou se preferirem do infundado - das condições para que o sistema jurídico-político possa ter força de lei. Soberano, pois, é aquele que decide no estado de exceção.

Niilismo e Estado, destruição dos princípios e questão da legitimação: para Schmitt (de acordo com uma vasta tradição de pensamento) a modernidade caracteriza-se por um poderoso processo de secularização, no qual o fundamento teológico tradicional é esvaziado do seu conteúdo religioso e transferido, em toda a sua vigência legitimadora, para o pensamento político no qual assume feição metafísica (no século XVII) e depois moral (XVIII), econômica (XIX), técnica (XX). Servindo para todos os fim, porém, a técnica produz niilismo; provoca a dissolução e a perda das referências tradicionais ligadas à terra que Schmitt, em um sugestivo escrito de 1942 intitulado Terra e Mar (Land und Meer), contrapõe ao mar para refletir sobre a história do mundo e traçar uma filosofia do devir na qual, atrás dos eventos políticos, jurídicos, históricos, as duas potências elementares e antagônicas operam secretamente. A técnica esgotou a terra, permitiu a conquista do mar e está abrindo para o homem um novo espaço de domínio, o ar. O homem dissolve, mas também espera, almeja um novo "princípio". A técnica, porém, não pode sê-lo; ela não se pode constituir como fundamento, ordem, valor. O que fazer, então, nessa época em que utopia e niilismo estão intimamente ligados? O único critério possível é a decisão soberana que define o "conceito do Político", que determina quem é "amigo" e quem "inimigo"; não o inimicus, aquele que nos é hostil na esfera pessoal, nem o rival, o concorrente, ou o adversário, mas sim o hostis, o inimigo da pátria, público, político, 
que é absolutamente "outro" e que na sua irredutível alteridade tem de ser enfrentado na luta, a única disposição estratégico-conflitual possível.

Ora, o niilismo não podia deixar de atingir a História, o horizonte das res gestae, o decurso linear, grandioso e progressista dos destinos humanos. Neste sentido, as obras de Cioran e Benjamin fornecem uma contribuição significativa. O olhar niilista do Angelus Novus desmascara o verdadeiro vulto dos fatos humanos; revela que as vitórias foram massacres; as ideologias, pretextos; o progresso, terror e queda; a História, cruento cortejo dos vencedores. Nas Teses sobre a filosofia da história Benjamin dissolve as ingênuas e cegas pretensões de uma visão determinista e evolucionista das res gestae, cujo ponto central é a idéia do caráter inevitável e positivo do progresso e a de um tempo homogêneo, vazio, linear. A este desmascaramento-dissolução segue a re-apropriação: é possível e necessário contar a história de outra forma, e dar-lhe um outro sentido. A tarefa do historiador materialista é a de elaborar um novo conceito de tempo, o "tempo de agora" (Jetztzeit), explicitamente inspirado na tradição judaica. A reivindicação benjaminiana do aspecto messiânico da história, a fundação de uma concepção descontínua do tempo, de uma temporalidade intensiva, torna-se, portanto, o lugar privilegiado de uma nova esperança, da utopia de um resgate do passado e da possibilidade de um outro sentido confiada às gerações de um futuro por vir.

O niilismo corrói a tensão entre história e utopia, tradição e revolução, passado e futuro. Relativismo, ceticismo, pessimismo, a "agonia do final" debilitam e esgotam o devir. Em outras palavras: se o niilismo contemporâneo conseguiu esclarecer a marteladas que a história não tem uma finalidade nem um sentido nem uma "vigência" universal, que as utopias do progresso, da legitimação, da totalidade e do absoluto devem ser denunciadas e rejeitadas, que não há mais horizontes únicos e estáveis de significação, então a história está morta e, usando a famosa definição de Jean-François Lyotard, os seus grands récits ${ }^{2}$, os seus metarelatos (iluminismo, idealismo, marxismo) sepultados. Irrompem em cena diagnósticos críticos do presente,

${ }^{2}$ LYOTARD, J.F. A condição pós-moderna, José Olympio, Rio de Janeiro, 1998. 
aparentemente crepusculares, que se encarregam de descrever a nossa época sob o signo do "fim da história" ou da "pós-história". Estes conceitos, já bastantes desgastados, muitas vezes considerados sinônimos ou misturados, foram utilizados por teóricos de direita e de esquerda e torcidos para diferentes fins. Entre eles devem ser lembrados Alexandre Kojève, cujos seminários parisienses (1933-1939) concentrados no momento da negatividade na Fenomenologia do espírito de Hegel marcaram uma inteira geração de pensadores, e Arnold Gehlen.

Como já aconteceu em Kant (o signo da revolução), Kojève procura no devir concreto dos acontecimentos humanos as bases do seu "fim da História". O signo é dúplice, no sentido que se divide em dois momentos. O primeiro mostra-se quando ele entrevê na revolução de 1917 e na ação de Stalin o fim da História. O segundo, que começa a tomar forma depois da Segunda Guerra, encarna-se no abrupto abandono de Stalin, "o Napoleão do marxismo" e na sucessiva conversão ao Napoleão autêntico, o grande vencedor da batalha de lena, cuja importância já havia sido sublinhada por Hegel: “eu errei - explica Kojève em uma entrevista (1968) publicada na Quinzaine littéraire -, Hegel estava certo quando viu no ano 1806 a data do fim da história". A vitória, o evento de lena, torna-se, portanto, o símbolo alegórico da inevitável e inabalável (para Kojéve) afirmação dos valores democráticos da Revolução francesa nos quais o Estado pode fundar-se e legitimar-se, em escala universal, como entidade que, superando e conciliando dialeticamente as contradições, os conflitos, as oposições, ergue-se-rá como o assassino da história, como o "espaço" dentro do qual se esgota toda possibilidade histórica ${ }^{3}$. A partir do fim dos anos cinqüenta, Kojève muda o foco do seu interesse; a sua análise re-molda, adapta o próprio centro messiânico, já indefensável, ao novo cenário internacional. O fim da história, agora, realiza-se na plena universalização da democracia liberal, capitalista e baseada no livre-mercado, que se encarna nas instituições políticas e econômicas dos Estados

\footnotetext{
${ }^{3}$ CF. KOJÈVE, A. Introduction à lecture de Hegel, Gallimard, Paris, 1947 (segunda edição em 1967), JARCZYK, G. e LABARRIÈRE, J.P. De Kojève à Hegel. 150 ans de pensée hégélienne en France, Albin Michel, Paris, 1996; AUFFRET, D. Alexandre Kojève. La philosophie, l'État, la fin de l'histoire, Grasset, Paris, 1990; VOLPI, F. Il nichilismo, op. cit.
} 
Unidos. A american way of life é "a maneira de vida própria da época post-histórica, já que a atual presença dos Estados Unidos no mundo prefigura o futuro 'eterno presente' da humanidade entendida na sua globalidade" escreveu na Introduction à lecture de Hegel.

Francis Fukuyama, cientista político norte-americano que se tornara internacionalmente conhecido, e criticado, pelas suas teses sobre o fim da História expostas depois da queda do muro de Berlim, utilizou incisivamente as idéias kojevianas e hegelianas.

A tese fundamental de Fukuyama, exposta no ensaio de 1989 O fim da História?, é notória: a dissolução dos regimes comunistas nos países do Leste Europeu demonstra que não é mais possível pensar em outras instituições que não sejam as da sociedade atual, liberal-democrática, industrial e capitalista. As exceções (a do mundo islâmico é uma dessas) e as resistências a este processo são liquidadas como um acidente de percurso que não teria a força nem o consenso nem os instrumentos para desviar ou impedir o fim da história, isto é, o equilíbrio e a "administração" do que já se possui, do que já foi alcançado ao término do violento, mas esclarecido caminho da modernidade. Em um artigo publicado poucas semanas depois dos atentados terroristas e niilistas (não foram poucos os intelectuais que usaram os dois termos juntos, equiparando, de fato, mais uma vez, o terror e o nihil) de 11 de Setembro Fukuyama, respondendo às críticas, explicou: "Permanecemos no fim da História porque há somente um sistema que continuará a dominar as políticas mundiais, o do Ocidente liberal e democrático. Isto não implica um mundo sem conflitos ou o desaparecimento da cultura como característica distintiva das sociedades. O conflito que enfrentamos, porém, não é o embate entre várias culturas, iguais e distintas, em luta entre elas, como as grandes potências da Europa do século XIX. O embate, hoje, consiste em uma série de ações de retaguarda da parte de uma sociedade [a dos regimes islâmicos] cuja tradicional existência é, na realidade, ameaçada pela 
modernização. A força da reação reflete a severidade de uma tal ameaça. Mas tempo e recursos estão ao lado da modernidade ${ }^{4}$.

Retomando e reelaborando idéias já presentes em Hendrik de Man e, antes dele, em Bertrand de Jouvenel e Agustin Cournot, o sociólogo alemão Arnold Gehlen fala explicitamente de um fim da história e de uma pós-história, principalmente nos ensaios A secularização do progresso (1967), Fim da história? (1974), A cristalização cultural (1961). Ao devir como progresso, desenvolvimento, dinâmica é contraposto um estado permanente de rotina, no qual será impossível operar transformações, produzir novas visões de mundo e que se assistirá à mera sobrevivência de esferas diferentes de atividades. O movimento da civilização tecnológico-industrial, malgrado oscilações, avanços e recuos, levou a um "estado de motilidade perpétua" em que tudo se reproduz e se repete incessantemente: é a "estase da história", é o seu fim, o seu "pós". Não há mais forças (filosofia, arte, religião) capazes de construir uma nova imagem de mundo; a civilização alcançou um estágio de cristalização cultural, de substancial paralisia. Na tentativa de esclarecer e dar plena dignidade filosófica ao conceito de pós-modernidade, Vattimo reformula as idéias de Gehlen. Na pós-história tudo tende a nivelar-se no plano da contemporaneidade e da simultaneidade; ela indica "a condição em que 'o progresso se torna rotina': as capacidades humanas de dispor tecnicamente da natureza se intensificaram, e continuam intensificando-se, a tal ponto que, enquanto novos resultados sempre se tornarão alcançáveis, a capacidade de disposição e de planejamento os tornará cada vez menos 'novos'. Já agora, na sociedade de consumo, a contínua renovação (das roupas, dos utensílios, dos edifícios) é fisiologicamente requerida para a pura e simples sobrevivência do sistema; a novidade nada tem de 'revolucionário' e perturbador, ela é o que permite que as coisas prossigam do mesmo modo ${ }^{5}$.

\footnotetext{
${ }^{4}$ FUKUYAMA, F. O fim da História depois de 11 de setembro. O artigo foi publicado em "The Wall Street Journal" e, em italiano, em "La Repubblica" de 19 de outubro de 2001.

${ }^{5}$ VATTIMO, G. O fim da modernidade, Martins Fontes, São Paulo, 1996, (introdução, p. XII).
} 
Rumo ao término do capítulo, é preciso examinar de um modo mais específico alguns pontos da reflexão de Gianni Vattimo, em que se condensam os efeitos mais significativos e originais de um "paradigma" niilista aplicado à (filosofia) política. Antes de tudo, a hermenêutica; uma posição filosófica cuja analogia com os problemas da democracia e da esquerda - em virtude das duas características principais que a determinam (definitivo afastamento do fundacionalismo metafísico e visão do mundo como conflito de interpretações) - não é acidental. Ao contrário: é a hermenêutica, quase sempre usada como sinônimo de niilismo (obviamente o niilismo consumado, perfeito de que fala Nietzsche), que pode oferecer à esquerda um solo teórico de referência para a sua ação de crítica da ordem política existente sempre atravessada, de resto, pela necessidade de se referir a algo que não fosse a mera efetividade. Em Hermenêutica e democracia (1994) o filósofo esclarece e precisa a sua posição: os traços caracterizadores da hermenêutica podem ser usados também para descrever o que acontece "nas democracias avançadas na atmosfera babélica da sociedade de mercado e no correlativo afirmar-se de identidade e pertencimento a comunidades naturais restritas - etnias, famílias, seitas, etc. - que tendem a explodir fora de todo controle e toda coordenação possível, produzindo fenômenos de dissolução do vínculo social” ${ }^{\prime 6}$ Nietzschianamente: a liberação da pluralidade de interpretações e das visões de mundo carrega intrinsecamente consigo uma tendência dissolutiva da coesão social. À caracterização da hermenêutica, porém, falta um terceiro, fundamental elemento que ficará mais claro se nos lembrarmos da fabulação do "mundo verdadeiro" que leva também ao desaparecimento do "mundo aparente": o antifundacionalismo da hermenêutica é, também ele, apenas uma interpretação e não "a constatação de uma estrutura 'objetivamente' multíplice da 'realidade'"; isto significa que ela, como todas as interpretações, deverá articular-se, explicar-se, argumentar e não só para justificar os seus conteúdos, mas, antes de tudo e principalmente, justificar o próprio estatuto de interpretação sem exibir fundamentos

${ }^{6}$ VATTIMO, G. "Ermeneutica e democrazia”, in: Nichilismo e emancipazione, Garzanti, Milão, 2003, p. 99. 
ou verdades. Em outros termos, mais lyotardianos: “o 'fim' dos metarelatos não deve ser visto (como parece acontecer no próprio Lyotard) como a descoberta de uma verdadeira estrutura do ser que excluiria os metarelatos; ao contrário, é preciso que ele se apresente como o efeito de um processo histórico do qual oferece uma precisa leitura"7 $^{7}$ a hermenêutica, em suma, como efeito de um processo niilista de consumição do ser metafísico, isto é, da violência. Mas como esse cenário teórico pode ajudar a repensar as razões (e as ações) políticas da esquerda?

Antes de tudo é preciso destacar o fato de que foram as filosofias da história, os grands récits do iluminismo, marxismo e positivismo, a inspirá-la, e não argumentos metafísicos. Reivindicar direitos com base em valores naturais, como posições políticas revolucionárias já fizeram, não é mais possível já que por um lado a referência à natureza, às essências, às diferenças e às igualdades se tornou explícito patrimônio das forças de direita; por outro, não se pode mais prescindir de uma crítica das ideologias que revele o caráter autoritário e violento da fundação de direitos e deveres em pretensas essências metafísicas. Reconhece-se uma forte afinidade entre hermenêutica e esquerda; aquela retoma a tradição desta que sempre reconheceu ao decurso histórico uma carga potencialmente emancipativa; diante da dissolução dos metarelatos, porém, a esquerda não soube oferecer uma interpretação diferente do devir, perdendo credibilidade e escondendo-se atrás de uma "genérica apologia do pluralismo" inconcludente e vazia, que não tem nada a dizer "na situação em que a democracia parece resolver-se na polaridade entre a cultura do supermercado e as identidades parciais vividas com furor fundamentalista" ${ }^{8}$.

Traços concretos desse cenário teórico: uma "esquerda niilista" não poderá fundar as suas reivindicações na tese metafísica da igualdade (que pretende pôr-se como idéia forte, capaz de revelar uma essência humana dada uma vez por todas, etc.), mas deverá apoiar-se no princípio da dissolução da violência, compreendida como afirmação peremptória última que, assim como qualquer fundamento

7 Ibid., p. 101.

8 Ibid., p. 104. 
metafísico-religioso, não admite interrogações ulteriores sobre o porquê, interrompe o diálogo, silencia. O argumento da igualdade ("que não é um fato natural, mas o seu oposto"; uma esquerda de projeto deverá corrigir com "leis adequadas as desigualdades naturais, isto é de nascença", isto é, priorizar as "condições de partida e não os resultados" ${ }^{\prime 9}$ ), de resto, demonstra-se praticamente ineficaz ao contrapor-se ao valor-chave da nova direita, isto é, a exaltação da concorrência em todos os níveis da sociedade como única garantia de crescimento e desenvolvimento. O princípio da dissolução (ou da redução) da violência é, ainda, o único capaz de doar novamente a palavra à esquerda sobre fenômenos essências das sociedades industriais avançadas: a cultura do supermercado e os fundamentalismos reativos. Às ameaças do fundamentalismo a esquerda, uma vez abandonada pela grande narração marxista, soube opor tão-somente, segundo Vattimo, a defesa do pluralismo fundada no direito à igualdade. Uma posição vigilante e crítica, mas incapaz de formular propostas e alternativas concretas; pode parecer paradoxal, conclui o filósofo italiano, "mas somente a adoção de uma perspectiva niilista pode dar à esquerda a capacidade de olhar de uma maneira não simplesmente defensiva e reativa a fantasmagoria do mundo pós-moderno"10 e de recuperar aquelas "dimensões utópicas" dos anos sessenta (Deleuze e Guattari, Marcuse) que a esquerda européia excluiu, talvez com alguma razão, mas sem refletir muito, do seu breviário de idéias.

Em novembro de 2002, por ocasião da entrega do "Prémio Hannah Arendt para o pensamento político", Vattimo profere uma longa conferência intitulada Globalização e atualidade do socialismo. Um terceiro pólo - o populismo - é essencial na economia da lectio que se abre justamente com a análise da "conexão causal" entre o processo de globalização e o "anarquismo endêmico" representado pelo populismo no global, que se manifesta como a única forma possível de resistência (raramente não violenta). A globalização nada mais é do que a redução da política à economia, ou, para usar as palavras de Habermas, a colonização do mundo da vida pela pura

\footnotetext{
${ }^{9}$ VATTIMO, G. "Sinistra di progetto" (texto de 1999), in: Nichilismo e emancipazione, op. cit., p. 111.

${ }^{10}$ VATTIMO, G. "Ermeneutica e democrazia", in: Nichilismo e emancipazione, op. cit., p. 106.
} 
racionalidade estratégica. Este é o núcleo da reflexão de Vattimo, que acrescenta: a única ordem internacional existente não é uma estrutura política, mas econômica.

Neste sentido, pensa-se que o único remédio à difusão da violência populista, cujos elementos se rebelam desordenadamente contra o império da pura economia, seja a formação de uma ordem política alternativa, igualmente integrada e globalizada. Tratar-se-ia, em suma, de idealizar, construir, organizar uma globalização política capaz de contrastar eficaz e efetivamente a "ideologia do Fundo Monetário Internacional" e o monopólio norte-americano. A pergunta é: uma entidade deste tipo teria alguma esperança de funcionar? A resposta populista - "que retoma e exprime muitos dos motivos de revolta presentes no anarquismo e na indisciplina social difusa, move-se ainda no horizonte da herança marxista e da sua idéia de uma revolução do proletariado mundial capaz de instaurar uma nova ordem, justa e humana. Foi formulada por último, em termos atualizados, por Michael Hardt e Antonio Negri no livro Império"11 $^{11}$ é descartada porque não se põe o problema do depois, da nova ordem que deveria seguir à revolução das multidões; por se limitar a uma apologia da "revolução permanente" e pela conseguinte falta de um projeto político-institucional.

A resposta federalista, que tem como pano de fundo o pensamento de Hannah Arendt, revela-se mais adequada para responder negativamente àquela pergunta e para se pensar o que está em jogo: a globalização econômica não se combate com uma globalização política, com uma política globalizada que acabaria por perder os traços da política autêntica, tenderia a cancelar (ou destruir) as diferenças e o almejo de uma "sociedade vivível". Ao contrário: é preciso resgatar a autonomia da política, libertá-la da economia e da esmagadora lógica do capitalismo; mas restaurar a autonomia da política nada mais é do que recuperar a substância ainda viva e atual da mensagem socialista. Não, como é óbvio, o socialismo "real”, "ideológico", metafísico, violento que desapareceu com a queda dos regimes do leste europeu, mas sim um socialismo niilista, capaz de preservar a autonomia e a dignidade da política, garantir o

${ }^{11}$ VATTIMO, G. "Globalizzazione e attualità del socialismo", in: Nichilismo e emancipazione, op. cit., p.125. 
equilíbrio das diferenças, respeitar a multiplicidade. É necessário que se efetive a passagem do liberalismo à democracia e, para Vattimo, ao socialismo: "para realizar de verdade os direitos de liberdade pregados pelo liberalismo é preciso não deixar que as coisas andem 'conforme os próprios princípios' (há um inaceitável naturalismo de Adam Smith!), por exemplo as leis de mercado, mas sim construir condições de igualdade que, ao invés, não são dadas 'naturalmente'”'12. 